Journal of Engineering and Applied Sciences 14 (21): 7809-7820, 2019

ISSN: 1816-949X

(C) Medwell Journals, 2019

\title{
Exploring Colors Inside the Dogma of 3D Malaysian Animated Film
}

\author{
${ }^{1}$ Dahlan Abdul Ghani, ${ }^{1}$ Nurul Mirza Syazwina Binti Rohizat and ${ }^{2}$ Luqman Bin Mohd Razali \\ ${ }^{1}$ Malaysian Institute of Information Technology, University Kuala Lumpur (UniKL), \\ 1016, Jalan Sultan Ismail, 50250 Kuala Lumpur, Malaysia \\ ${ }^{2}$ University, Inovasi 1-1, Jalan Teknokrat 1/1, 63000 Cyberjaya, Selangor, Malaysia \\ dahlan@unikl.edu.my
}

\begin{abstract}
Color is a concept that philosophers, artists and scientist have historically spent a great deal of time exploring and quantifying. Also, color can really define the enhance the mood in $3 \mathrm{D}$ animated film. Color is a powerful and persuasive communication tool that can significantly impact the message in 3D animation in Malaysia. The purpose of this research is to study the color effects and meaning in 3D animated film in Malaysia. This study will focus into several aspect of color such as colortype, expression and emotion. Animated characters can take any color and even deciding on the color of their faces can be significant decision.
\end{abstract}

$\underline{\text { Key words: } \text { Color, 3D animation, animated character, color effect, expression, significantly impact }}$

\section{INTRODUCTION}

Wayang kulit is the first animation in Malaysia. It shows character movement which is controlled by Dalang through the joints of the hand, neck and mouth are movable. Animation in Malaysia was beginning with the establishment of Malayan Film Unit in 1946 and it has produced Hikayat Sang Kancil in 1978. Meanwhile in 1937, Disney created the first sound and color animated feature film Snow White and the Seven Dwarfs. Animation and color have coevolved, since, their respective inceptions. Color has been both a distinct challenge as well as a space for animation's history. Color is the property possessed by an object of producing different sensation on the eye as a result of the way it reflects or emits light.

In animation, colour can effects our emotions and it makes it a great storytelling tool. Color can make animated short film, so, much more visceral, especially when use it boldly. According to Lin Chin Chen, color and background information would affect the third grader's achievement in memory and comprehension differently while both the sixth and eighth grader's performance were not affected by the amount of visual complexity in motion visuals at all. There are many definitions of animation. The most obvious source of one, Webster says "a: animation is a motion picture made by photographing successive positions of inanimate objects (as puppets or mechanical parts). Animated cartoon, a motion picture made from a series of drawing simulating motion by means of slight progressive changes." Animation can be defined as a motion picture made by photographing successive positions of inanimate objects (such as puppets or mechanical parts) or an ani-mated cartoon or film made from a series of drawings simulating motion by means of slight progressive changes. There are different types of animation including $2 \mathrm{D}$ and $3 \mathrm{D}$ animation. $2 \mathrm{D}$ animation is the traditional animation method that has existed, since, the late 1800 s. It is one drawing followed by another in a slightly different pose, followed by another in a slightly different pose, on and on for 24 frames a second. Example of animated film that use 2D animation is Snow White and the Seven Dwarfs and The Little Mermaid from Disney. 3D animation consists of varying properties of a 3 dimensional scene defined in numerical quantities. A 3D Model can change properties such as position, rotation, shape and surface style. An animated 3D scene is defined by the change of these numerical properties through time. Apart from 3D objects, a scene contains a camera (point of view) and lights which can also be animated. In order to create an animation each "state" of the 3D scene needs to be rendered to create a frame (Akimoto, 2014).

There is some different methods to create animated short film and one of them is 3D animation. 3D animation also referred to as CGI animation. It made by generating images using computer graphics that create a series of

Corresponding Author: Dahlan Abdul Ghani, Malaysian Institute of Information Technology, University Kuala Lumpur (UniKL), 1016 Jalan Sultan Ismail, 50250 Kuala Lumpur, Malaysia, dahlan@unikl.edu.my 
images that forms an animation. CGI means computer generated images, so, it can easily mean both static and dynamic images using computer graphics. From John Lasseter, "computer don't create computer animation any more than a pencil creates pencil animation. What creates computer animation is the artist."This research focus on the color in 3D animation in Malaysia. One of the purpose of color is to improve object recognition (Ibrahim et al., 2013). We recognize object more quickly when colors reflect what we see in the physical world. The aim of this study, this study the important of color in 3D animation in Malaysia. As a conclusion, color is a very important element in animation because color can effect our mood while we watching animated film.

Literature review: Colour wheel is a circle shape that divided in to 12 sections with each section displaying a different color, according to its pigment value. Figure 1 all colors are created from the three primary colors which is red, green and blue (Santoli, 2015). The primary colors are shown forming a triangle within the color wheel. The color wheel shows the relationship between the primary colors, secondary colors and complementary colors. In Malaysia, $3 \mathrm{D}$ animation is a new thing, for example, BoBoiBoy and BoBoiBoy Galaxy by Animonsta, Upin Ipin by Les Copaque, Ajen Ali by WAU Animation, Didi and Friends by Digital Durian. All this short film use a different color concept. First, BoBoiBoy is a animated series, centering on a boy who has elemental-based superpowers and the ability to separate into three. BoBoiBoy Galaxy is a rebranding effort for the BoBoiBoy animation series which tell a story about 14 years old boy name BoBoiBoy who got super powers from a robot orb name Ochobot. He has the power of seven elements which is lighting, wind, earth, fire, water, leaf and light Fig. 2 and 3.

For first animated series of BoBoiBoy, he has three transformation which is lightning, wind and earth. BoBoiBoy lightning use yellow and orange color. One of the BoBoiBoy episode show that he changes from BoBoiBoy lightning to BoBoiBoy thunderstorm. BoBoiBoy thunderstormuse black and red colour. Orange associated with joy, sunshine and the tropics. Orange represents enthusiasm, happiness, creativity, attraction, determination and stimulation. Orage is not as aggressive as red. We can see when BoBoiBoy change from BoBoiBoy lightning to thunder storm which is from orange color to red color. This is because, red is the color of fire and blood, so, it is associated with energy, war, danger, strength, power, determination as well as passion, desire and love Fig. 4 and 5.

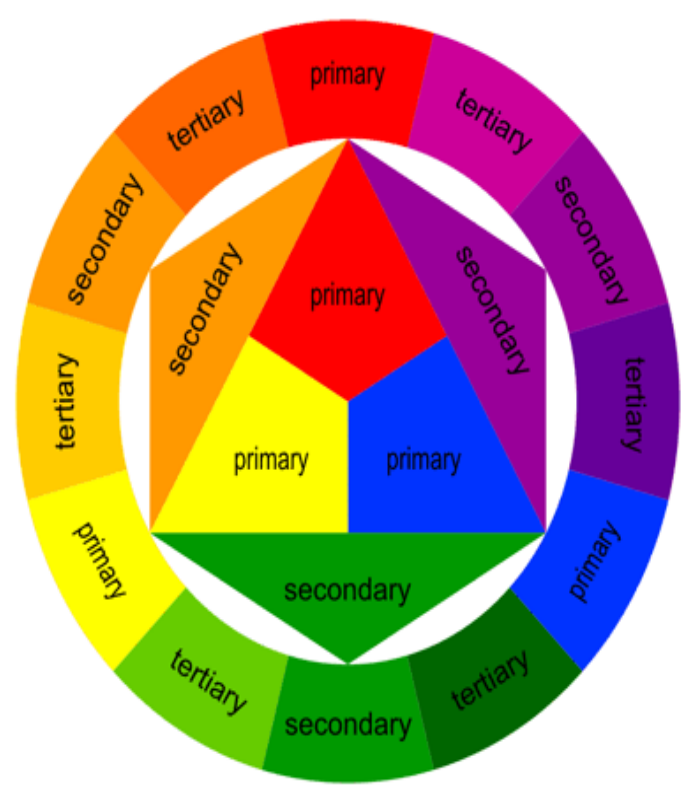

Fig. 1: Example of colour wheel

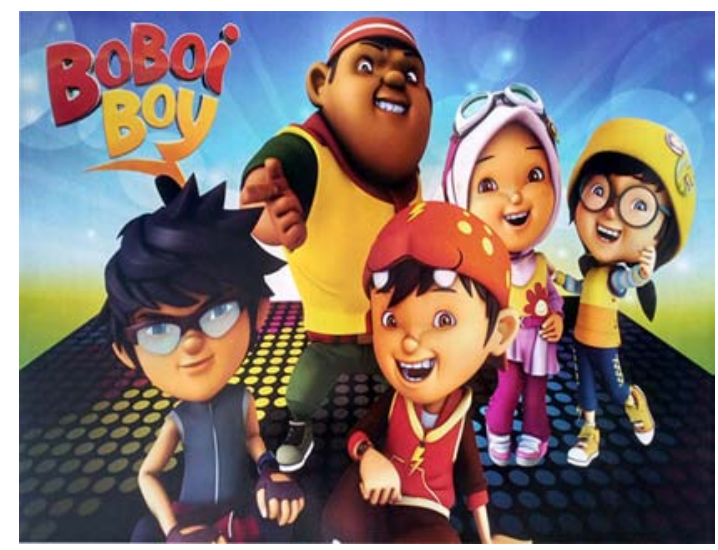

Fig. 2: BoBoiBoy (first product of Animonsta Studios)

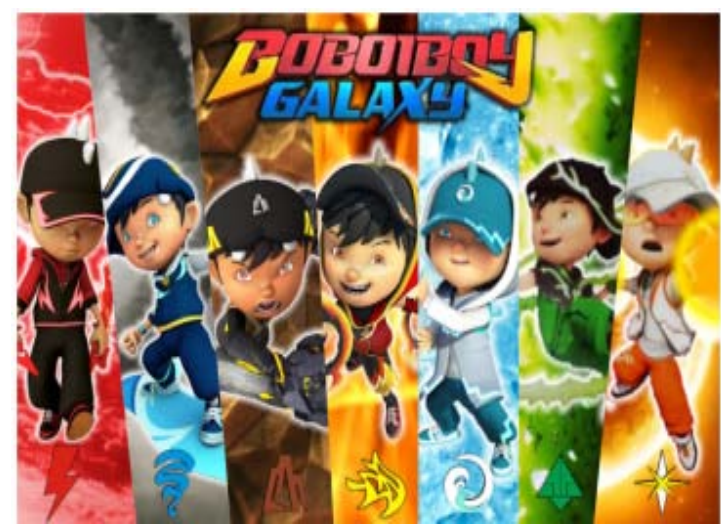

Fig. 3: BoBoiBoy galaxy (rebranding from BoBoiBoy animated series) 


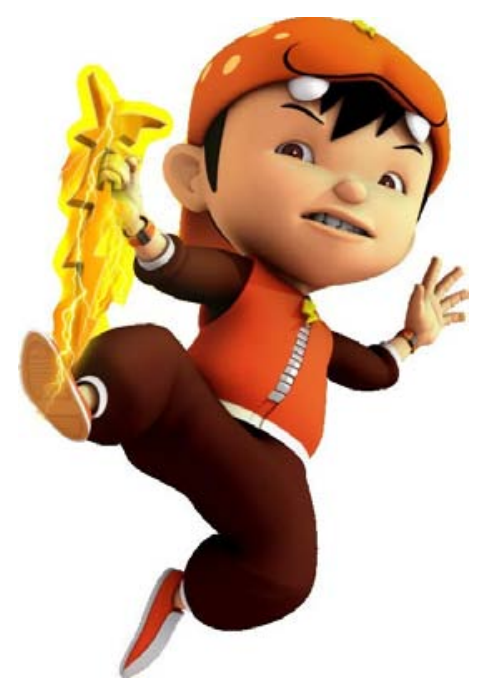

Fig. 4: BoBoiBoy lightning

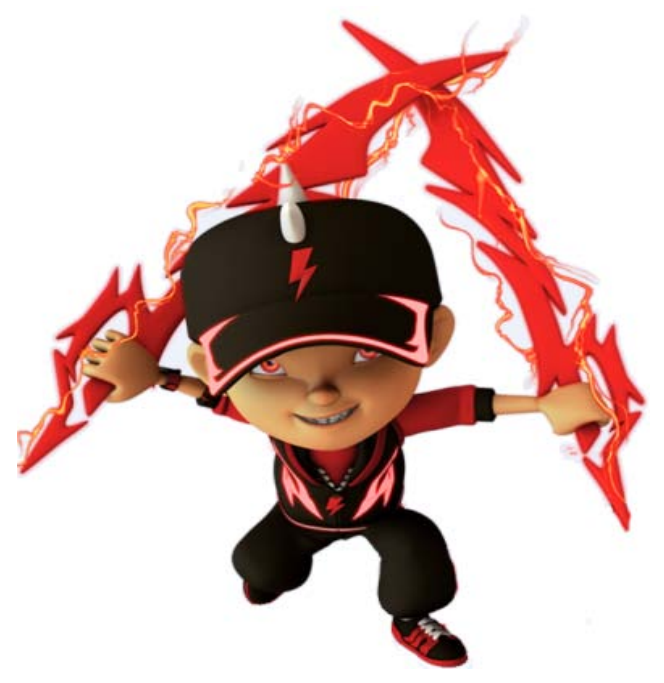

Fig. 5: BoBoiBoy thunderstorm

Second, BoBoiBoy can transform to BoBoiBoy wind. BoBoiBoy wind use yellow colour. Yellow is the color of sunshine, hope and happiness. Yellow stands for freshness, positivity, clarity, energy, honor, loyalty and joy but on the other, it represents cowardice and deceit. Besides that, yellow may represent caution and sickness. Third, BoBoiBoy Earth. BoBoiBoy Earth use brown and orange color. Orange symbolizes energy, vitality, adventure and warmth. Darken oranges offer a sense of comfort like some are earthy. Brown color says stability, reliability, dependability and approachability. It is the color of soil, growth, fertility and Earth. It is associated the concept of all natural and organic. Brown is the color of the earth Fig. 6-8. Didi and friends is an animated series

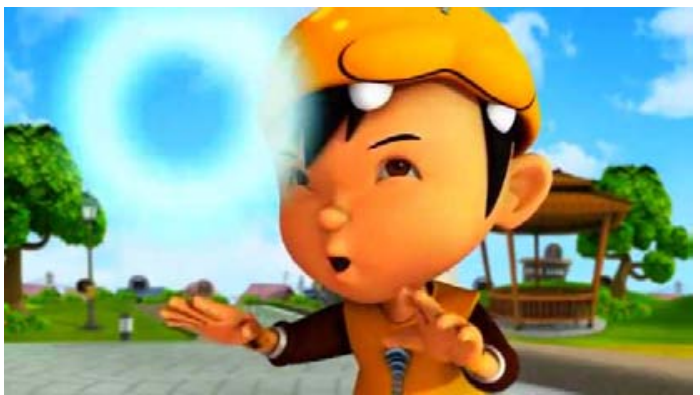

Fig. 6: BoBoiBoy wind

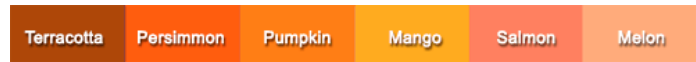

Fig. 7: Color scheme
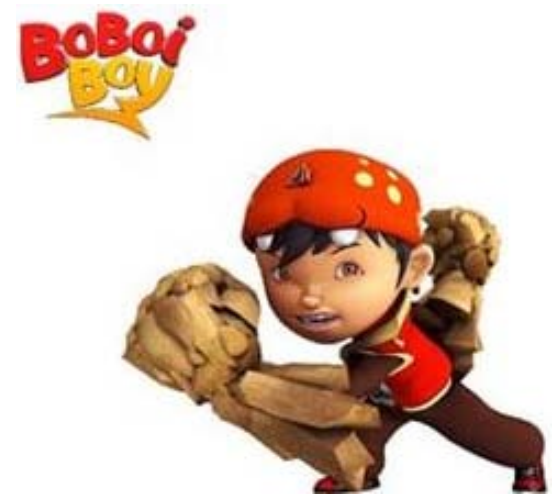

Fig. 8: BoBoiBoy earth

that entertain children between 0-6 years old. The animated series is published by Digital Durian. The main character of Didi and Friends is Didi, Jojo and Nana. They were inspired by a serama. Serama is a unique chicken with small body. His chest forward and tail up. Didi have brown skin and wearing red hat with "Didi" word in yellow color. Didi also wearing blue line red belt. Jojo have white skin and Jojo wear purple glasses with green clothes. Nana wear ribbon on her head and she wear pink clothes. Nana also wearing yellow necklace with the letter of "N" in pink color Fig. 9.

Between Didi, Jojo and Nana, Didi is the leader. This is because Didi have a lot of primary color element on his body. Red, yellow and blue are primary color. Primary color are the root of every other color imaginable (Anders, 2014). The primary pigments used in the manufacture of paint come from the pure source element of that color. There are no other pigments blended in to alter the formula. The main character or leader in animated short film will have a primary color on their body or their costume. Other than that, Didi and Friends use a bright color to attract children. This is because this 


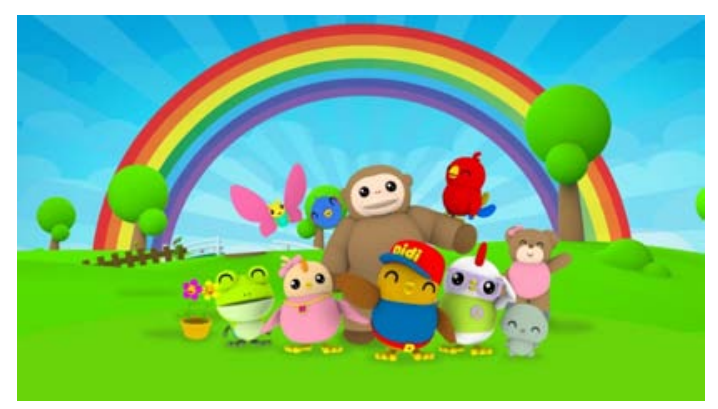

Fig. 9: Malaysia's 2D animated series "Didi and Friends"

short-animated film is suitable for children below 6 years old. For example, Didi and Friends have a colorful background with bright green color and it have a colorful rainbow. This may attract children to watch short animated film with the importance of color vibrant (Anders, 2014). In this study, a quantitative analysis was performed to exploring color perception and emotion in $3 \mathrm{D}$ animated film in Malaysia. This chapter describes and discusses how the researchers will gather the necessary data and information that will be use in the entire study. Method that used in this study is primary and secondary, analysis, data comparative, visual research and observation.

The model structure of the lighting hue and saturation and the treatment for each subject: In this study, a quantitative analysis was performed to determine the effect that lighting color has on emotional arousal as observed by physiological responses. The study performed was a mix of a crossover design and an incomplete block design that tested a large number of treatments across multiple subjects. The dependent variable in the study was Electrodermal Activity (EDA) as measured by a GSR sensor Fig. 10 and 11. The GSR sensor used in this study was the Affectiva Q Sensor. Higher EDA suggests a higher emotional involvement in the subject. There were 2 different videos that were shown and there were 21 Versions of each video with variations in the lighting hue and saturation. A total of 42 treatments were administered. Each subject only viewed 5 treatments of each video for a total of 10 viewings. In order to eliminate the effect of viewing order a pre-determined set oftreatments was applied to each subject. Subject 1 received treatments 1 through 5 , subject 2 received treatments 2 through 6 and so on. Thus, each video was viewed 5 times and each video was viewed in all be possible orders. The viewing order was strictly controlled due to the fact that the order of viewing can have an effect on thee motional state of the viewer. Both videos shown were short clips, under $20 \mathrm{sec}$ long and we

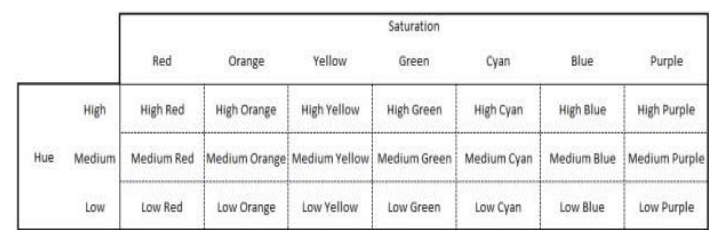

Fig. 10: The table of the lighting hue and saturation

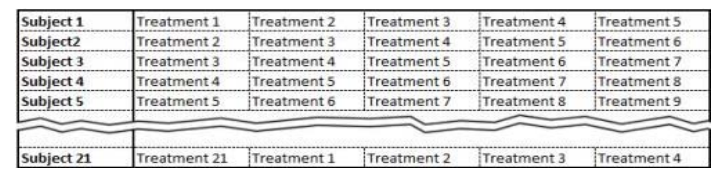

Fig. 11: Treatment for each subject

redesigned to present a strong display of a single emotion. In order to test a similar range of emotions that one might see in an feature length animated $1 \mathrm{~m}$, a strong positive and strong negative emotion were chosen. The RST video portrayed the emotion love and the second video portrayed the emotion sadness. GSR data were recorded along with data from a pre-test survey and apost-test survey. Survey data was not included in the statistical analysis. This study utilized a descriptive-correlational method. It described the color perception and preference through the 3D animated film in Malaysia as well as determined the type of color, color emotion and expression, purpose of color, effect of color and color perception. Additionally, it also determined color in background, character and layout (Anonymous, 2005).

\section{MATERIALS AND METHODS}

Figure 12 structure for exploring color perception and preference through. Red, yellow and blue are the primary colors. Primary colors are the most basic colors. You can't make them by mixing any other colors. Orange, green and purple are the secondary colors. A secondary color is made by mixing two primary colors. For instance, if you mix red and yellow you get orange (Kendall, 2013) Fig. 13 and 14.

\section{Value; tints and shadesa:}

- The lightness or darkness of a color is called its value

- The value of a color can find by mixing its tint and shades

- Tints: light values that are made by mixing a color with white for example, pink is a tint of red and light blue is a tint of blue

- Shades: dark values that are made by mixing a color with black. Maroon is a shade of red and navy is a shade of blue (Fig. 15 and 16) 


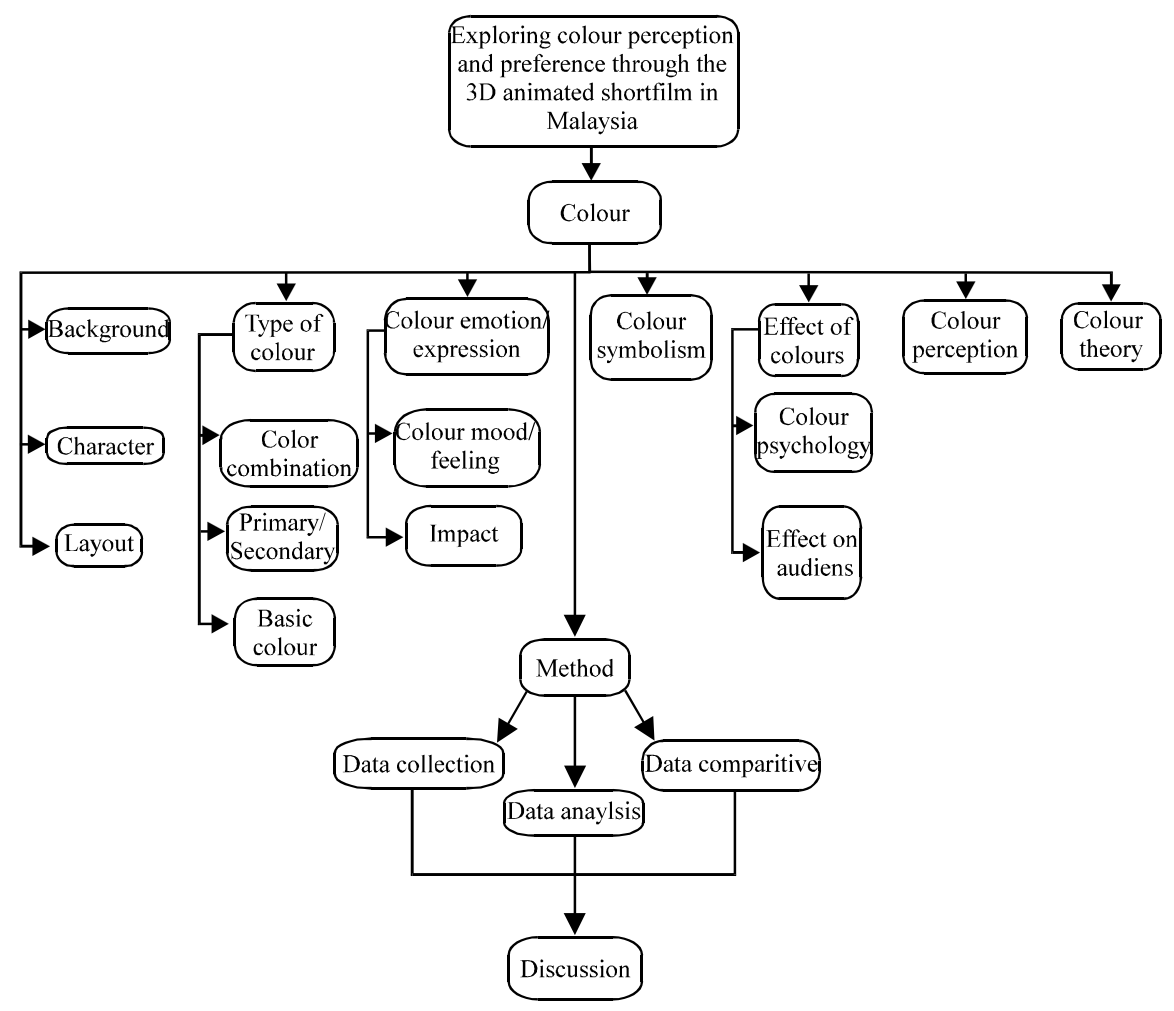

Fig. 12: Structure for exploring color perception and preference through the 3D animated short film in Malaysia

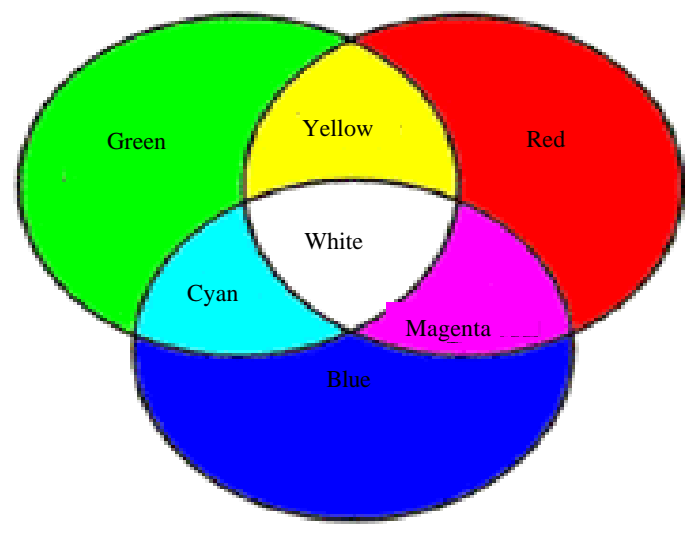

Fig. 13: Additive color mixture of blue, green an red to produce cyan, magenta, yellow and white (Two or more colors can be added together to produce new color composed of the mixture of the initial colors used. This can be demonstrated on a white screen with three colors which is blue, green and red; cyan, magenta, yellow and white are formed from the mixture of these colors (Fig. 13). One of the requirements in choosing colors to be used in color mixing experiments is that two of them cannot be mixed it produce the third)

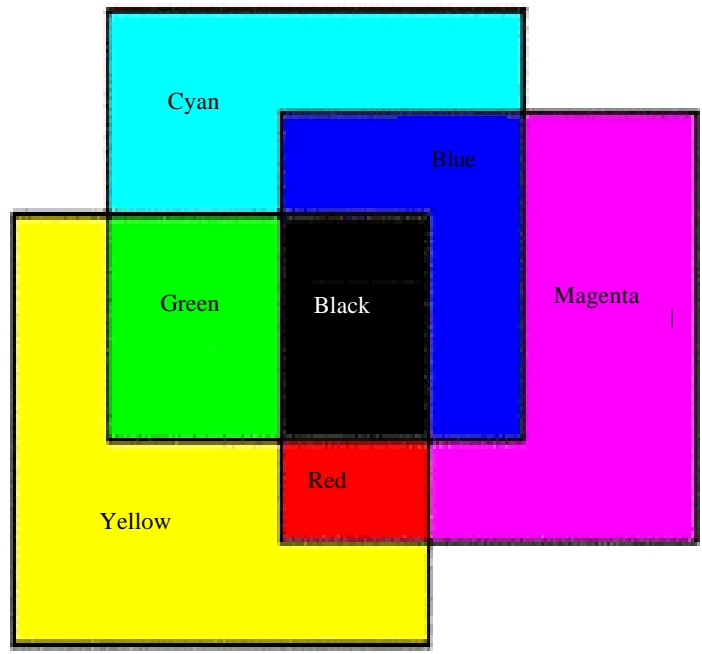

Fig. 14: Subtractive color mixtures of cyan, magenta and yellow to produce blue, green and red. (Subtractive color mixtures involve the selectively absorption of wavelengths. Cyan, magenta and yellow are subtractive primaries. If white light was shone through a yellow filter, the yellow filter will absorb blue and transmit red and green (which makes yellow) 


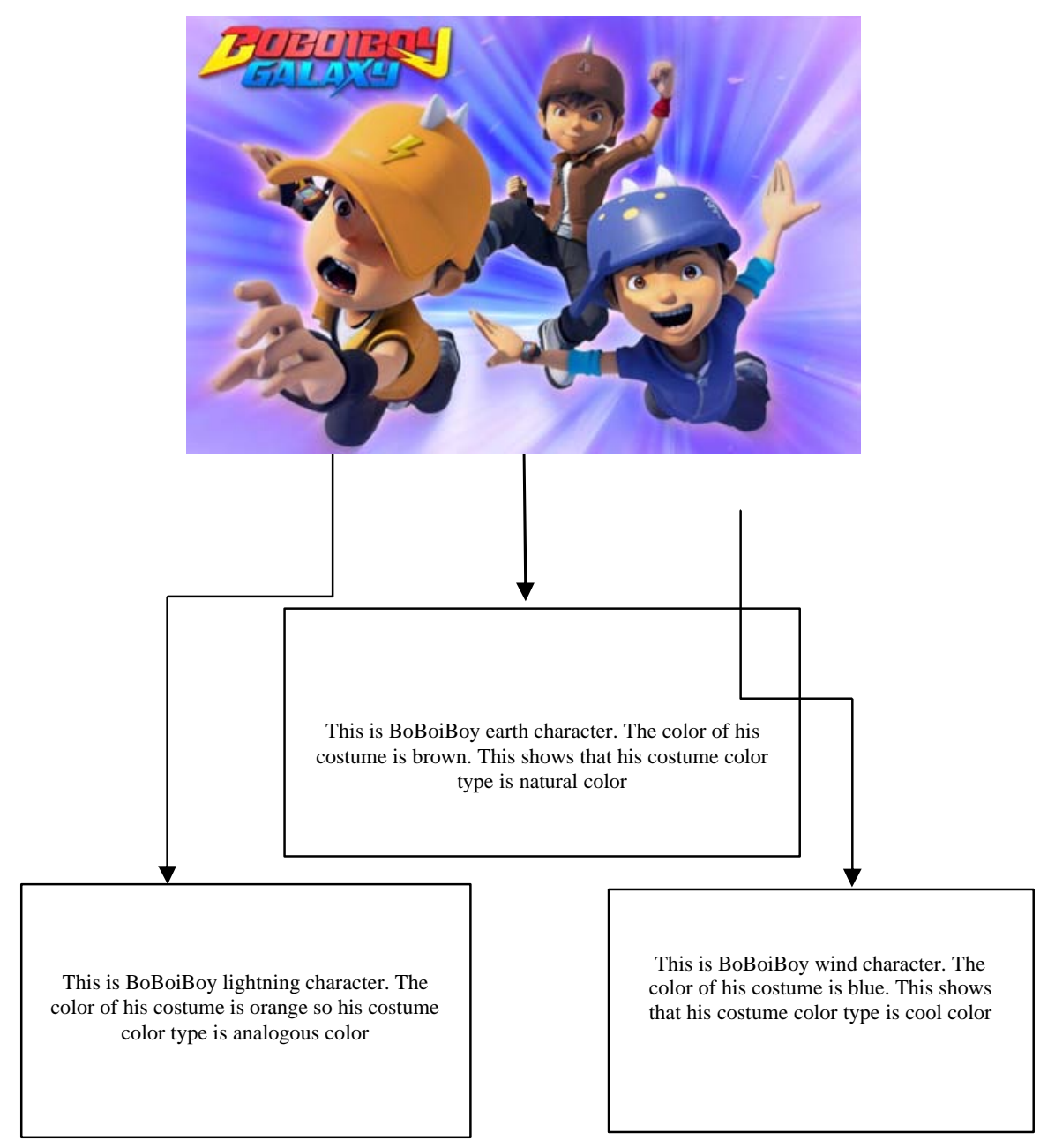

Fig. 15: BoBoiBoy galaxy in three character

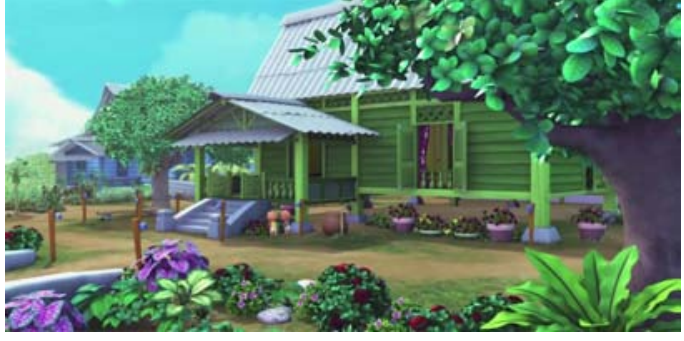

Fig. 16: Upin Ipin background

\section{Complementary colors:}

- Colors that sit opposite each other on the color wheel

- Red and green are an example of complementary colors

- Because they are opposites, they tend to look especially lively when used together when you put complementary colors together, each color looks more noticeable

\section{Analogous colors:}

- Color sit next to each other on the color wheel

- They tend to look pleasant together because they are closely related

- Orange, yellow-orange and yellow are an example of analogous colors

\section{Natural colors:}

- Natural colors don't usually show up on the color wheel

- Naturall colors include black, white, gray and sometimes brown and beige

- They are sometimes called "Earth tones"

\section{Warm colors:}

- Warm colors are made with red, orange, yellow

- Warm colors tend to make we think of sunlight and warmth 


\section{Cool colors:}

- Cool colors are made with blus, green, purple

- Cool colors might make we think of cool and peacefull things like Winter skies and still ponds

In Malaysian 3D animated short film, they use a lot of colot to make audience more interested to their animation. In this research, I use BoBoiBoy, Ejen Ali, Upin Ipin and Didi and Friends to know more about color. This is the example type of color that applied in 3D animation in Malaysia.

\section{RESULTS AND DISCUSSION}

Interview: My first step to do this research is interview head of section research and innovation, Dr Dahlan Abd Ghani. My purpose to do this interview method is to collect more information about my research. I collect the information from research study, research structure and other recorces. Dr Dahlan Abd Ghani give a lot of tips and input about color. Other than that, $i$ also get a tips in how to make a good research methodology (Fig. 17).

Observation: In this research, first I do an observation to all the animation which is BoBoiBoy, Upin Ipin, Didi and friends and Ejen Ali. For me, Youtube is the best medium to watch all the animation in every episode. I can do a review and observe the diffrences color between all animation, effect of color, color perception and type of color. Besides that, from Youtube I can observe the character background and layout of the animation. I can pause the video, if I want to look more detail about the animatio Fig. 18-22.

This is the color comparison between Upin Ipin, BoBoiBoy, Didi and Friends and Ejen Ali animated film. (Table 1) there is a cycle of changing colors that affects us through the different stages of life. These are reflected in our changing colour preferences. Children have colour likes and dislikes, according to individual character and stage of development. Strong, bright colours have the effect of shocking the baby's inner vibrations which can make the baby unsettled and restless. Bright, intense colours such as primary red, yellow and orange can stop a child from sleeping well and cause them to cry. Bold patterns and strong contrasting colours are also likely to be over-stimulating in large doses, so, for a small infant soft tones of yellows or creams, peaches or pinks which radiate warmth and peace are emotionally soothing and comforting.
Though soft blues and pinks have traditionally been used for baby rooms, creamy yellows, peachy apricots and minty greens are also excellent colours for both genders (Fig. 23) Green is calming but can be cold when used as a wall colour, especially in a south facing or dark room. Yellow or blue-based greens create differing effects. Blue-based greens are good as a cooling element in a hot north/west facing room. The fresher yellow-based greens are beneficial when used as an accent in soft orange or red rooms. This will add a balance to colours that are warming aand astimulating. aBlues aon atheir aown acan aalso be cold but can be used as a wall colour with contrasting warm colours in drapes, mats or bed linen. Clear pastels to mid-tones of blue are less cold and more appealing. Very dark blues are not recommended for young children as their intensity relates to DARK and can cause nightmares. Comfort colours for very young children are pinks, peaches, pale almond beiges and lavenders as these equate to love and security Fig. 24-25.

Soft fruity coral reds and violet blues are good for social areas as they create inspiration and imaginative play. Reds are generally not as good for the implementation of ideas into concrete goals as they stimulate abut adon't encourage achievement. Violets open both sides of the brain-both the logical and the creative and children often do their most interesting work when small amounts of this colour are present. Like dults, children have distinct personalities and colours that appeal to their souls. This means that some achildren who are active and outgoing are happy in brightly coloured rumpus/playroom. It may not however be what they need in a learning environment.

Scaling down the bright hues they ask for to softer versions might be a wise thing. Work or study areas should ideally be decorated in more muted colours. Less energetic or more sensitive children might always be attracted to softer, paler colours but may need cleaner, sharper colours in a learning environment to activate them. Grey is not recommended as it is a hue with no direction or purpose. It is neutral and indecisive. White as a standalone colours in a learning environment is chilly and needs to be used as an accent to contrast with pastels or bright colours.

Asserting individuality and growth spurts, both physically and emotionally are typical a of a this time (Fig. 26). Teenagers go through an identity crisis and often use black to hide this as they feel it is cool. Black needs to be combined with other colours if it is to be used 


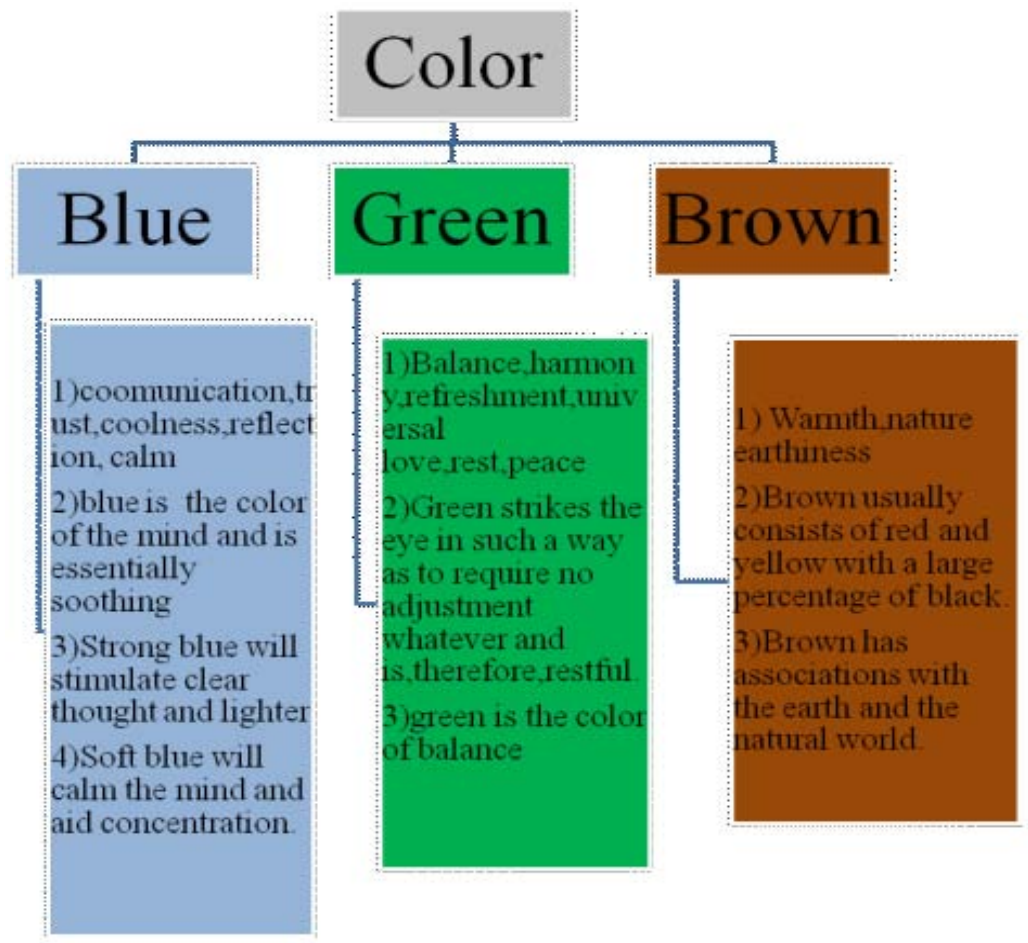

Fig. 17: Types of colour that applied in 3D animation

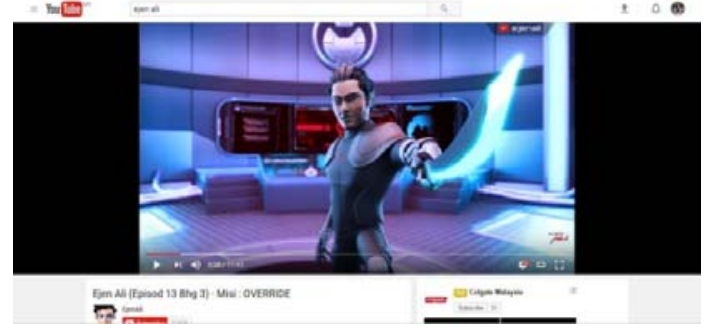

Fig. 18: Ejen Ali (The background of Ejen Ali short film looks more crucial with the purple, blue and red color)

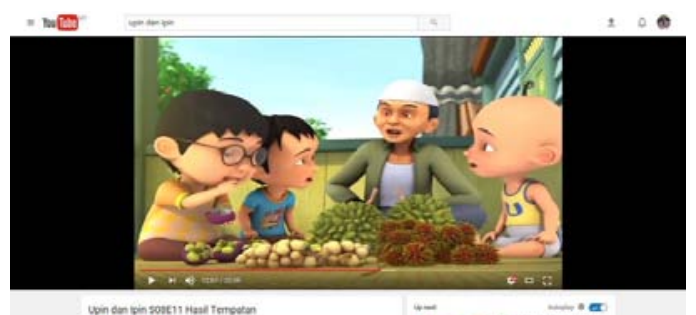

YNan

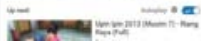

Fig. 19: Didi and Friends Malaysian animated film (The background of Didi and Friends is more colorful and it give a happening mood to children)

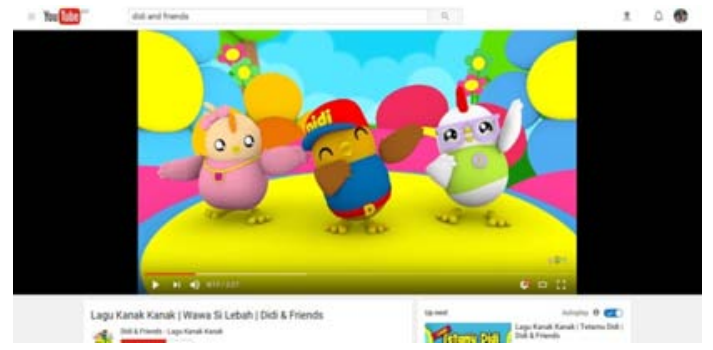

Fig. 20: Upin Ipin Malaysian 3D animated film. Upin Ipin background shows more of Malaysian typical visualization and notion resembling Malay

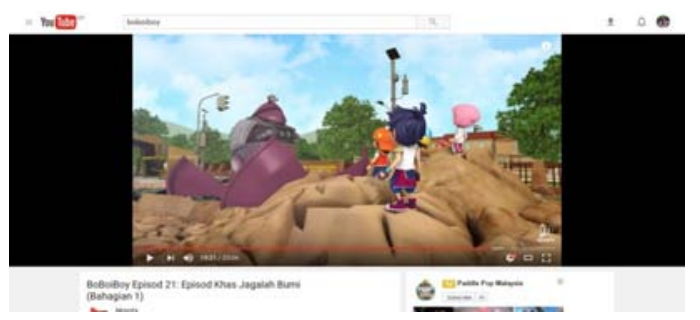

Fig. 21: BoBoiBoy Malaysian 3D animated super hero. BoBoiBoy season 1 show more to environment background. Their battle always be at their school or their places 
Table 1: Color comparison and variant

\begin{tabular}{lll}
\hline List of animation & Explanation & Colors \\
\hline Upin Ipin & $\begin{array}{l}\text { Color that use in Upin Ipin animated film is a colorful color. A lot of bright color in this animation. This } \\
\text { is because children had positive reaction to bright color }\end{array}$ & $\begin{array}{l}\text { Green, blue, } \\
\text { yellow, red }\end{array}$ \\
& $\begin{array}{l}\text { BoBoiBoy is a superpowers animation. In BoBoiBoy animation,the color they use is more to natural color. } \\
\text { The color is sutable for their concept which is superpower However, BoBoiBoy is still able to attract } \\
\text { children to watch }\end{array}$ & Brown, orange, green \\
Didi and Friends & $\begin{array}{l}\text { Since, Didi and Friends is an animated series that entertain children between 0-6 years old. The color that } \\
\text { use in this animation is really bright and colorful. Recognizing the colors and identifying the color names } \\
\text { is an important part of child's development. Although, Upin Ipin has }\end{array}$ & $\begin{array}{l}\text { Red, yellow, blue, pink, } \\
\text { blue, purple }\end{array}$ \\
& $\begin{array}{l}\text { a colorful background as Didi and Friends but Didi and friends focus more on bright color animation compare } \\
\text { to Upin Ipin. This is because Didi and friends audience's target age is from 0-6 yers old }\end{array}$ & \\
In Ejen Ali animation, red and blue color plays an important role in this animation. Red is the color of energy & Red, blue \\
Ejen Ali & and power, so, it related to Ejen Ali as MATA agent. Then, blue color is widely use in background & \\
\end{tabular}

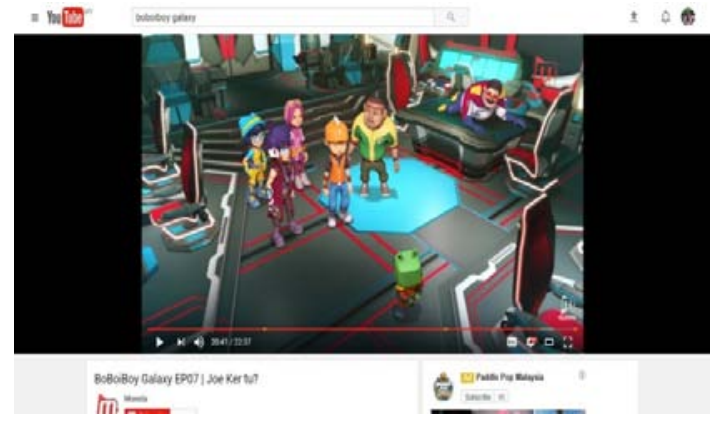

Fig. 22: BoBoiBoy Galaxy Malaysian 3D animated super hero. BoBoiBoy Galaxy has more dramatic background, since, the storyline had change from BoBoiBoy

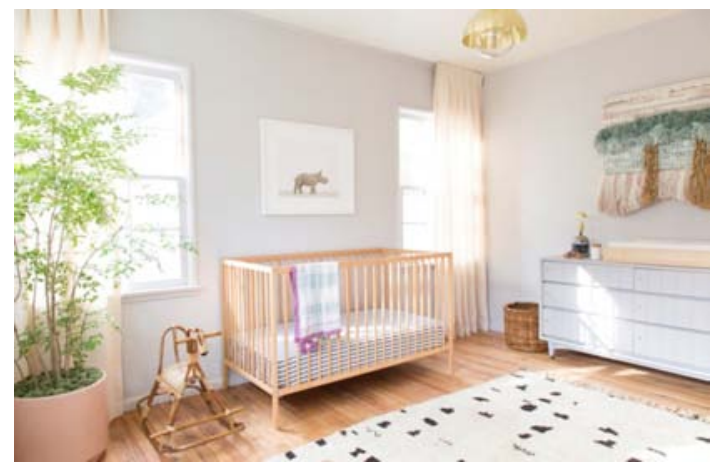

Fig. 23: Baby's room

as it is not beneficial to emotional development. It is without light. Using small amounts of fluoro brights will lift the young person away from the feeling of isolation or withdrawal from the world. Red is a favorite bright for this age group-intense energy. Bold blues and citrus greens also provide some tranquility. Purple is usually embraced when the mind develops social awareness and outward thoughts-this is later in the teenage years, usually between 14-17 years old. Texture and changing sheens in fabric (matt velvets to silky satins) offer a positive tactile experience to teenagers as well as being seen to be desirable from a cool point of view. At this age, a fixation with metal and glass in all forms is prevalent-car fetishes with young boys and jewelry with girls Fig. 27.

Older people can be drawn to soft pastels but they may not have the vitality of hue needed to stimulate the mind and mood. Eyesight problems can also impair how the colour is seen and what is seen. Softer shades of reds and oranges are warming and can help with circulation and energy levels. Peaches, apricots, warm tans, terracotta's and pinks can also be used for this purpose. Reflecting on the past and thoughts of a spiritual future can also be reflected in colour choices. Soft blues, lavender mauves and violets are colours that connect to the spiritual or reflective mood. It is interesting to note that blue rinsed hair tints and lavender water are the province of the elderly lady. Studies carried out in nursing/rest homes indicate that soft pinky-beiges contrasted with soft blue/greens are soothing and peaceful. The judicious use of floral pattern can evoke the tranquility of ruralc life and the simplicity of times past Fig. 28.

Significance study: The findings of study are to show the benefit of color in animation or how color change people perspective towards physical and mental with the usage of color that be used in Malaysia animated film whether $3 \mathrm{D}$ or $2 \mathrm{D}$. Color is become important role not only in animation but also include in our daily life. Every color represents their characteristic and style. For example, if some people choose or liked Cyan, a greenish-blue coloris symbolizing relaxation, restful or calm. But for researcher, the main of study is to know how color was used in Malaysian animated film such as Upin Ipin, BoBoiBoy, Didi and friend and Ejen Ali to examine how Malaysian with different ages attract to any of their animation. 


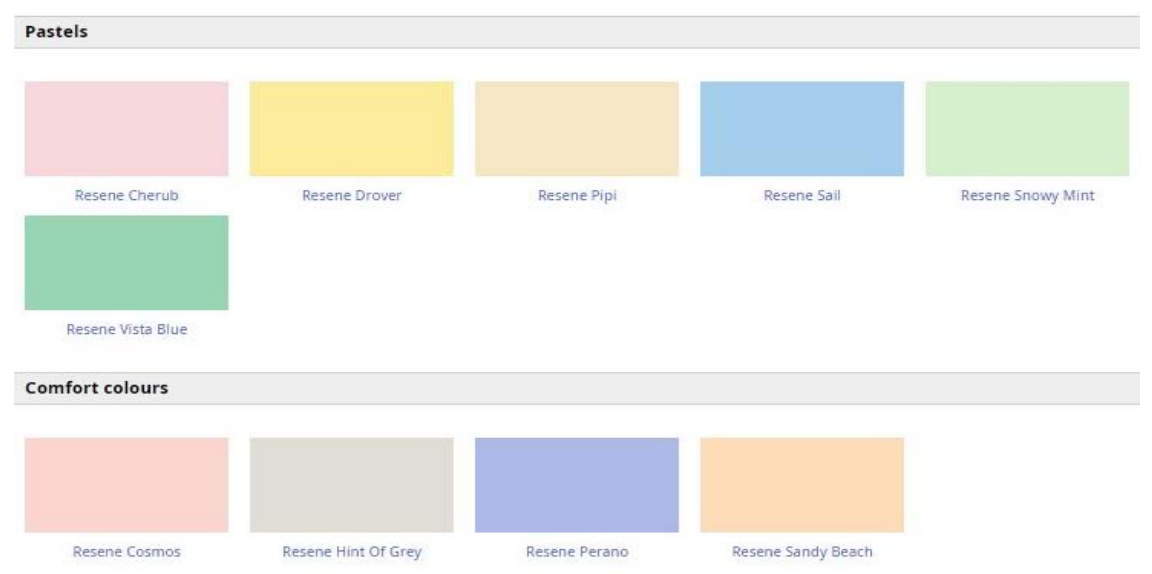

Fig. 24: Colors variant for babies

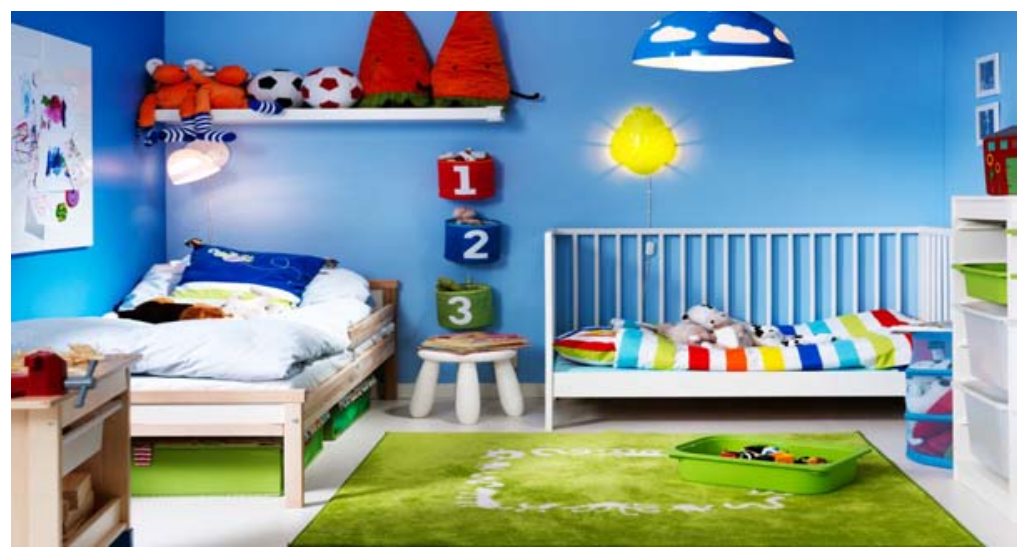

Fig. 25: Children room visualization and environment

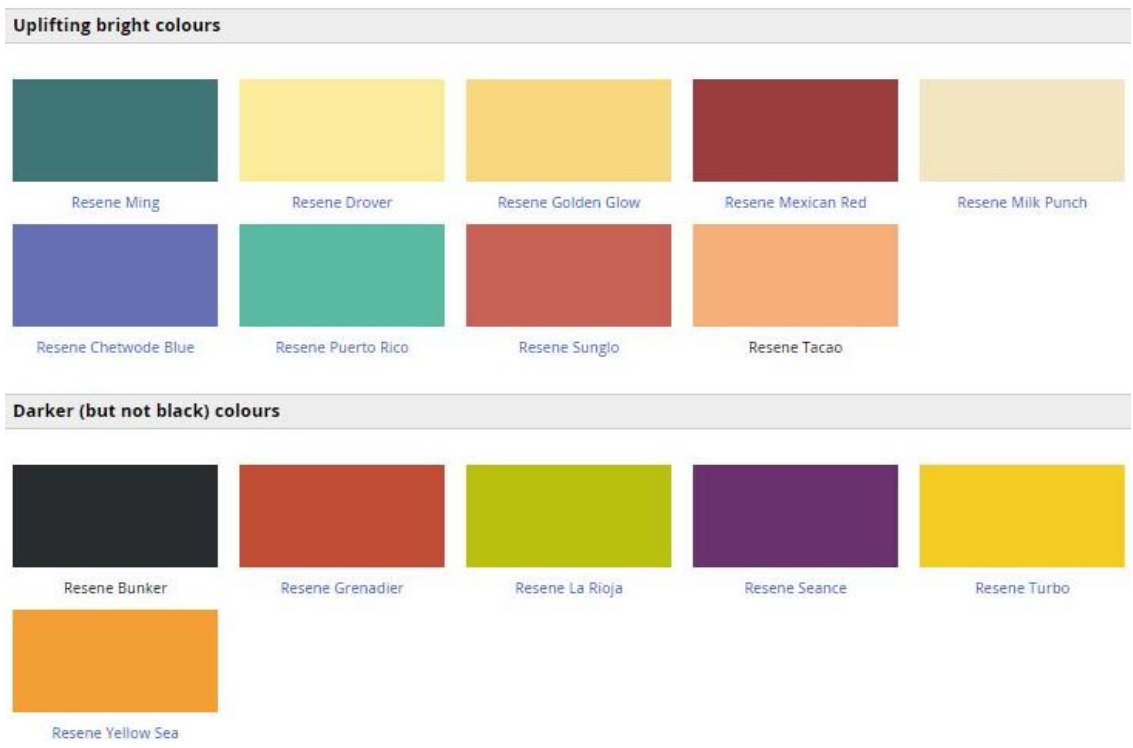

Fig. 26: Vivid colors thumbnails 


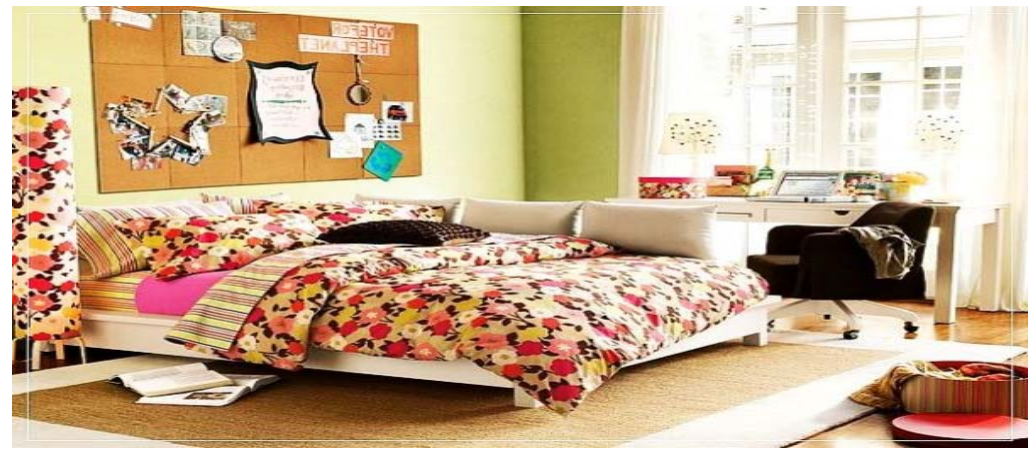

Fig. 27: Youth room environment and color

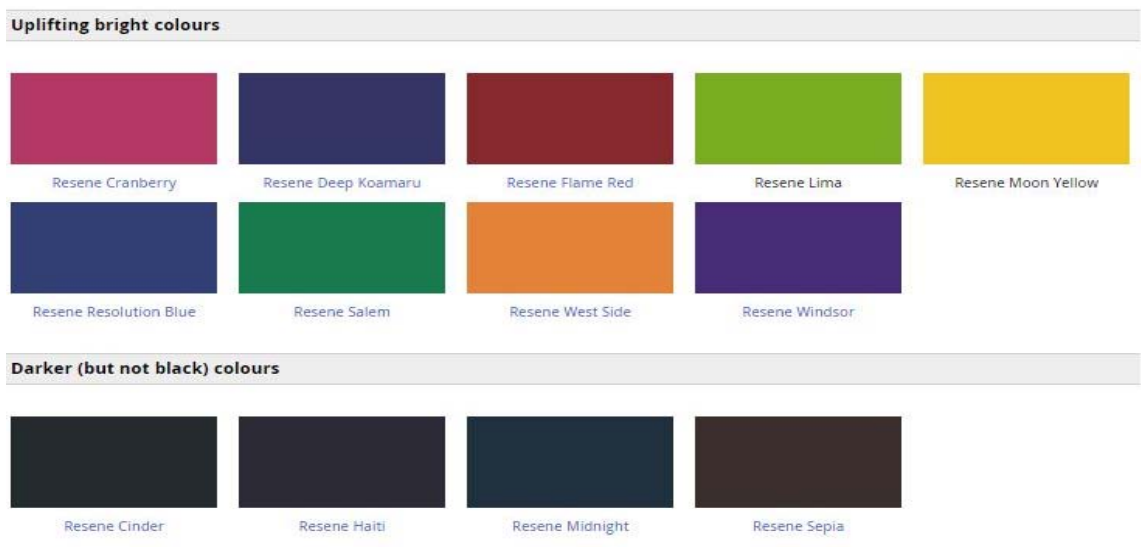

Fig. 28: Color that affects the mood of youth

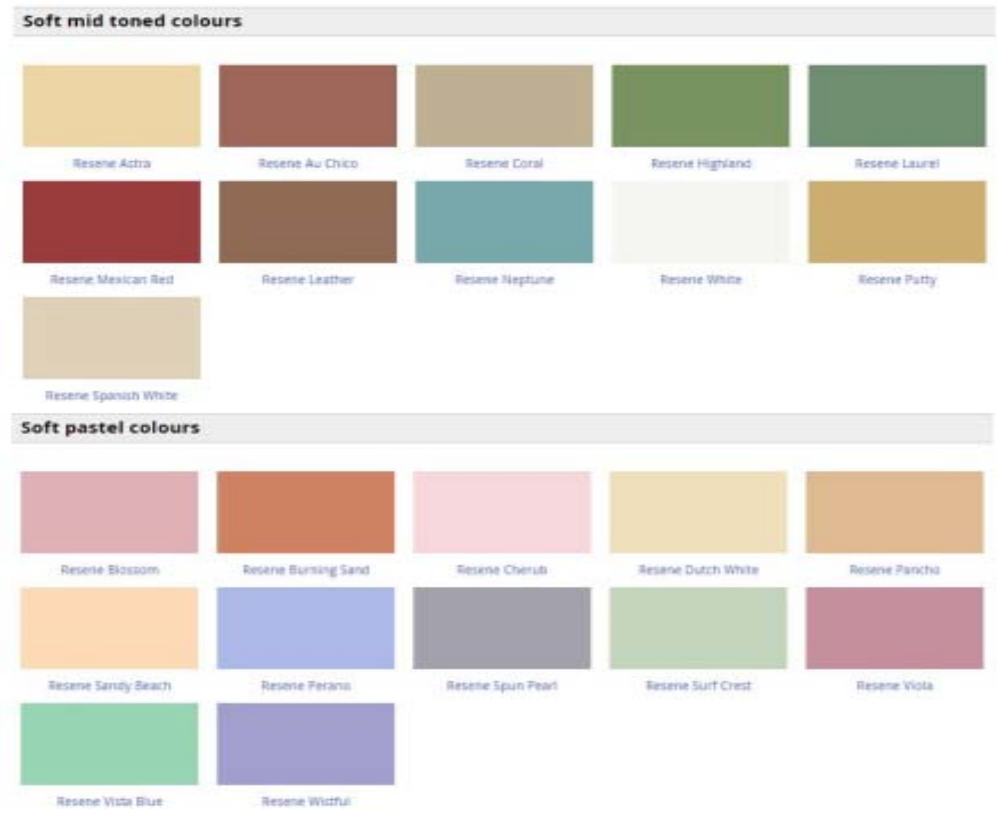

Fig. 29: a, b) Color that suitable for old people 


\section{CONCLUSION}

Color is the property possessed by an object of producing different sensation on the eye as a result of the way it reflects or emit light. Color can make animated short film, so, much more visceral. Color is an element of visual language that people process before they are consciously aware of it. Because color is a strong element of visual communication. We need to think through how and why we are using it. There is a lot of animation audience's target like kid and teenager. Every audience need a different color to attract them to watch the animation. In animation, color is are define as most tacit visualization process to attract children attention.

\section{REFERENCES}

Akimoto, D., 2014. Peace education through the animated film Grave of the Fireflies physical, psychological and structural violence of war. Ritsumeikan J. Asia Pac. Stud., 33: 33-43.
Anders, C.J., 2014. Don't deprive yourself of seeing the beauty of Princess Kaguya. Gizmodo Media Group, New York, USA. https: //io9 . gizmodo . com/dont deprive-yourself-of-seeing-the-beauty-ofprincess-1648552243

Anonymous, 2005. Walt Disney's creative flowchart he gave to his employees. Rebrn.com, USA. https://imgur.com/gallery/6a7eX3x

Ibrahim, N, W.F.W. Ahmad and A. Shafie, 2013. A cproposed model for animation of Malay folktales for children. Proceedings of the International Conference on Information Systems, December 2-4, 2013, Sepuluh Nopember Institute of Technology, Surabaya, Indonesia, pp: 243-248.

Kendall, P., 2013. Kaguya hime no monogatari: The other side of Studio Ghibli Review. WordPress.com.,USA. https://soranews24.com/2013/11/26/kaguya-hime-n o-monogatari-the-other-side-of-studio-ghibli- $\% \mathrm{E} 3 \%$ 80\%90review\%E3\%80\%91/

Santoli, E.A., 2015. Hayao Miyazaki's drawing and watercolor technique. Fanboys Anonymous, USA. http://www.fanboysanonymous.com/2015/01/haya o-miyazakis-drawing-and-watercolor.html 